\section{DUAL \\ MODALITY \\ MAMMOGRAPHY AND ULTRASOUND REFLECTION TO IMPROVE ACCURACY OF BREAST CANCER DETECTION}

Khusnul Aina, Deddy Kurniadib, Suprijantob, Oerip Santosoc

aBiomedical Engineering, Airlangga University, Surabaya, Indonesia bPhysics Engineering, Institute of Technology Bandung, Bandung, Indonesia

cSchool of Informatics, Institute of Technology Bandung, Bandung, Indonesia
Article history

Received

15 December 2019

Received in revised form

10 May 2020

Accepted

20 May 2020

Published online

22 June 2020

*Corresponding author k_ain@fst.unair.ac.id

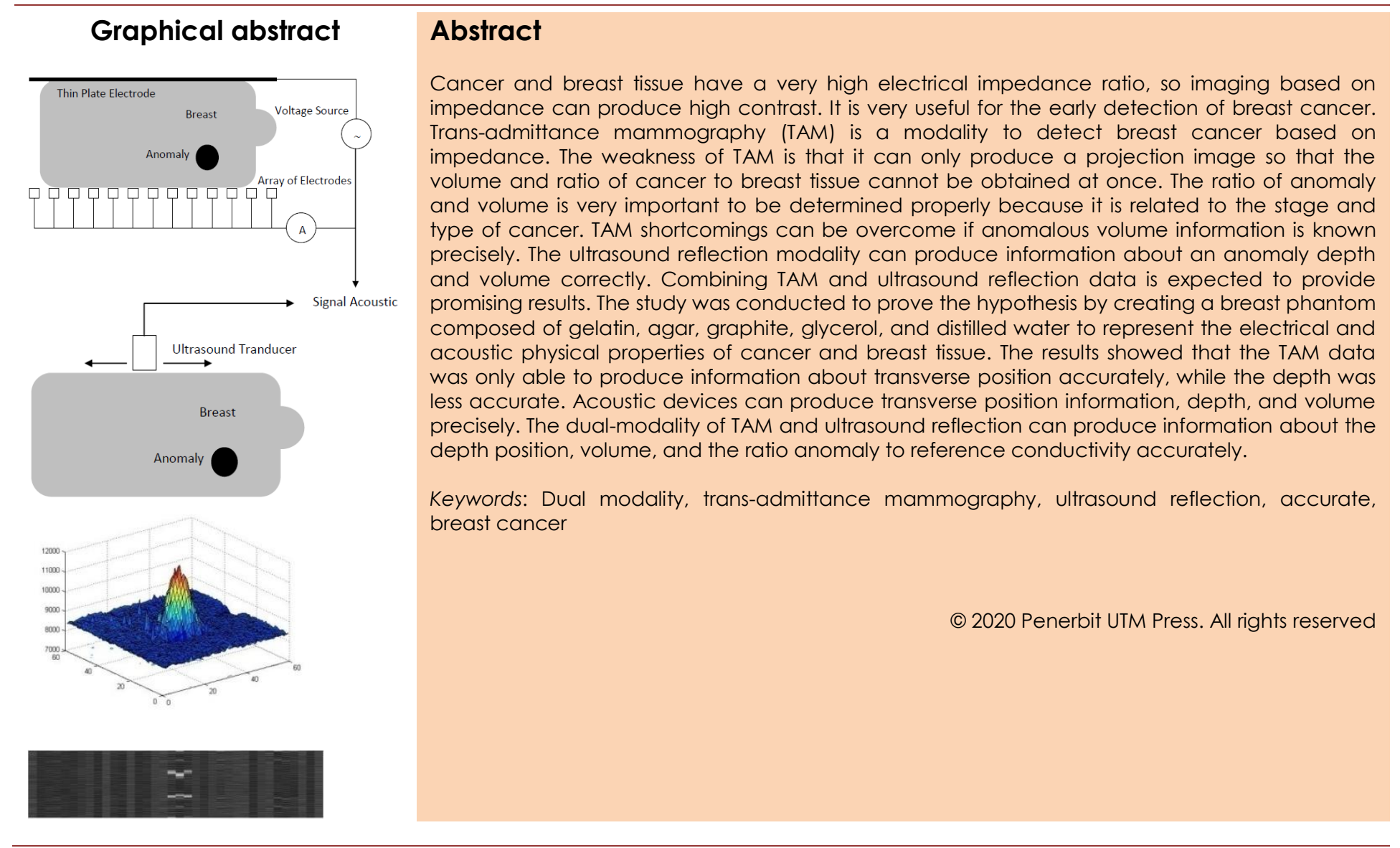

\subsection{INTRODUCTION}

Based on Globocan data, it is stated that there were 12.7 million cancer cases and 7.6 million estimated deaths caused by cancer in 2008 globally. Breast cancer is one of the most frequent types of cancer diagnosed in women and caused of their death, about $23 \%$ of the total cancer cases and $14 \%$ of the 
total deaths from cancer [10]. Based on data from the American Cancer and Society, it is stated that the number of breast cancer increases by age. The more aged woman, the higher the risk for breast cancer [5]. Therefore at 40 years old, women should check the condition of her breasts regularly every year $[15,21]$.

The earlier detection and treatment, more women with breast cancer will be saved $[13,18]$. Therefore, WHO recommends two programs that must be done to combat breast cancer. They are education and screening programs. Education means helping women to be able to recognize the signs of breast cancer manually and immediately report it to the hospital.

To conduct the screening process, it requires medical equipment that is capable of detecting the presence of breast cancer early. Some equipment has been built to detect the presence of breast cancer, such as x-ray mammography, breast ultrasound, and MRI mammography $[8,21,13]$.

Mammography is a medical instrument that is commonly used to detect breast cancer, but this equipment has some disadvantages which often give negative or positive false information and the dangers posed by radiation due to the use of X-rays for the breast [23]. Early detection using mammography equipment will double the risk if it is done at the age of 40 to 50 years, and the risk will increase up to the age of 75 years [4].

The ability of ultrasound to detect breast cancer is less accurate than x-ray mammography, although ultrasound capability has progressed in recent years. However, because it is much more flexible and users can scan the desired area repeatedly from various angles, the ultrasound is often used to investigate suspicious anomalies near the surface of the skin or cyst. It is generally used in diagnostic purposes to check the type of tumor on or as a monitor to help the placement of the biopsy needle [7].

MRI mammography is rarely used for early detection of breast cancer because it is high-cost. Generally, MRI is only utilized for diagnosis verification. It is only used for early detection when the X-ray mammography procedure is not possible, for example in the case of young women who generally have still dense breasts or women with high risk when she is exposed to X-ray radiation [7].

The tissue impedance properties have long been an interesting study because changes in the electrical impedance of the organs are associated with physiological and pathological properties. Both physiological and pathological properties are closely related to medical application information $[14,9]$.

Some experiments showed that breast cancer has a lower impedance than the normal breast tissue so that the imaging impedance-based can be used as an alternative instrument to detect breast cancer $[24,11,19,6]$. This is also supported by studies that have been conducted by Zoa and Gua that in the future, electrical impedance tomography (EIT) will replace the X-ray mammography as medical equipment for early detection of breast cancer [27].

Intensive research of electrical impedance has been done since the 80s. in the 2000s, they have produced several prototypes of medical devices for the application of early detection of breast cancer based on EIT [3, 2], such as Z-Tech Breast Scan, TS2000, MEIC, EIS breast imaging, TAM, which each of the equipment developed by MIT, Israel, Russia, Dartmouth University and IIRC (Impedance Imaging Research Centre) Kyung Hee University.

When each type of equipment is operated separately, it will have a detection accuracy that is similar to the accuracy of breast cancer early detection equipment. However, because the devices based on EIT have different basic information from the existing equipment, then to be able to detect breast cancer with better results it is recommended to combine EIT with other cancer indicator techniques $[27,12,1]$.

It has proposed a detection algorithm to obtain the transversal position, depth, and size of breast cancer anomalies that can be used in TAS (transadmittance scanning) and TAM (Trans-admittance mammography) $[16,17,22]$. However, TAS and TAM are only able to produce electric current mapping, so that the accurate results are only obtained by the transversal position. Meanwhile, the depth position is difficult to obtain accurately, even the volume and the ratio between the conductivity anomalies and references have never been obtained. So that information from TAS and TAM is limited to the transversal position, depth, and size of the anomaly prediction based on the prediction ratio $[26,25]$. Both the volume and the ratio of anomalous information are very important to be determined precisely because it is associated with the stage and type of cancer information.

Acoustic data can obtain information on the transversal position, depth, and volume anomalies appropriately. By combining the information of depth and volume from acoustic data with TAM data is expected to give promising results for the two systems non-ionizing completely and accurate information i.e. the transversal position, the position of depth, volume, and type of anomaly.

Here, the proposed topic is to increase the accuracy of breast cancer early detection between TAM which has high contrast and acoustic information which has a high spatial resolution. It is assumed that the combination of two the information above will obtain anomaly information completely and accurately.

This paper is divided into 4 sections. Introduction (Section 1) talks about the importance of research was conducted so that there is a hypothesis that the combination of two TAM and UR modalities is complementary so that produced complete and accurate information. The methods (Section 2) talk about the steps taken to prove hypotheses that include constructing phantoms that have electrical 
and acoustic properties resembling tissue and breast cancer, comparing the results of each modality, i.e. TAM, UR, and TAM-UR modality. The result and discussion are explained elaborately in Section 3, followed by the conclusion in Section 4.

\subsection{METHODOLOGY}

The study begins by reviewing equation of transversal position, depth and volume anomalies which have been derived by Seo et al. (2004), as follows:

a. Tranversal position ( $\left.x_{0}, y_{0}\right)$, is position of

$$
\max \left|g(x, y)-g^{0}(x, y)\right|
$$

Where $g(x, y)$ and $g^{0}(x, y)$ are trans-admittance data of frequency $\omega$ and $\omega 0$

b. Depth position (zo) can be obtained from identity,

$$
\frac{\left|g(a, b)-g^{0}(a, b)\right|}{\left|g\left(x_{0}, y_{0}\right)-g^{0}\left(x_{0}, y_{0}\right)\right|}=\frac{\left|2-\frac{d^{2}}{z_{0}^{2}}\right|}{2\left(\frac{d^{2}}{z_{0}^{2}}+1\right)^{5 / 2}}
$$

where $d=\sqrt{\left(x_{0}-a\right)^{2}+\left(y_{0}-b\right)^{2}}$ and $(a, b)$ is the position of the point $\left(x_{0}, y_{0}\right)$.

c. If the ratio of $\tau_{2} / \tau_{1}$ was known, then volume of anomaly will be obtained,

$$
|D|=\frac{\pi\left|2+^{\tau_{2}} / \tau_{1}\right|\left|z_{0}\right|^{3}}{\left|1-^{\tau_{2}} / \tau_{1}\right|} \frac{\left|g\left(x_{0}, y_{0}\right)-g^{0}\left(x_{0}, y_{0}\right)\right|}{3 g^{0}\left(x_{0}, y_{0}\right)}
$$

where $\tau_{1} / \tau_{2}$ is ratio of conductivity or admittance between anomaly and normal.

From the TAM devices, the transversal position can be directly obtained from trans-admittance data in Equation (1), on the other hand, the anomaly depth can be indirectly got from trans-admittance data in Equation (2), so its accuracy is determined by the accuracy of the trans-admittance data. Anomalous volume can be calculated from Equation (3), but it requires data of the ratio between the conductivity anomalies and reference. The ratio cannot be obtained from TAM. Therefore, the anomalies volume is estimated from the data of ratio between the conductivity anomalies and reference [26].

The device of reflection ultrasound can directly obtain the transversal position, depth position, and anomaly volume from ultrasound reflection data so that the information can be obtained accurately. A combination of ultrasonic reflection data and transadmittance will generate information of transversal, depth position and volume anomalies accurately as well as the ratio between the anomalies conductivity and references previously unknown. Two of the last information is the most important parameter to determine the stage and type of anomalies in the breast.

Besides, a combination of these devices is expected to be applied to analyze the object of the multi anomaly. The high contrast from transadmittance data can be used as a guide to obtaining the transversal position of anomalies correctly. The information of the transversal position is then used as the prior information on the ultrasonic reflection data to obtain the position of the depth and volume anomalies more accurately. By using Equation (3), information on the depth and volume of anomaly can be used as initial information to obtain the ratio between the conductivity of anomalies and reference. The three activities and analysis in this study can be displayed as a block diagram in Figure 1.

Review equation:

1. Tranversal position $\left(x_{0}, y_{0}\right)$

2. Depth position $\left(\mathrm{z}_{0}\right)$

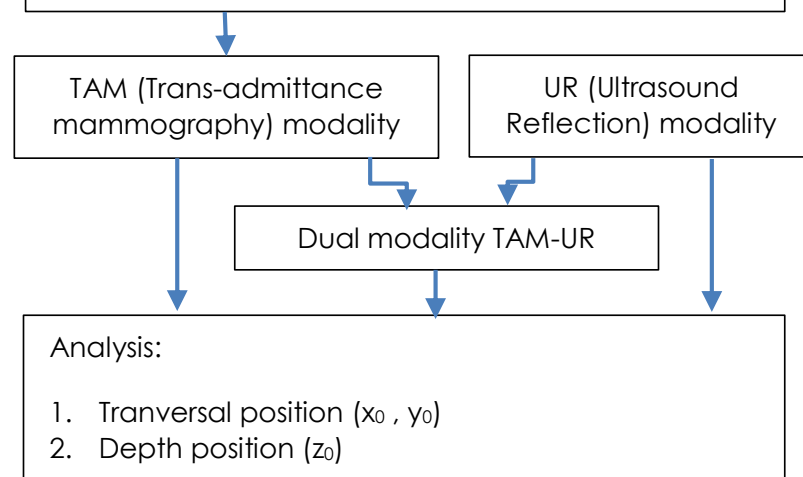

Figure 1 The three activities and analysis in this study

The devices used in the study are the immersion ultrasound sensor $1 \mathrm{MHz}$, signal generator, amplifier (Usip-12 Kraut Kramer), digital oscilloscope, computer, Impedance/Gain-phase analyzer, and TAM multi-frequency.

Real samples are very complex because the composition of the breast does not only consist of two phases, i.e cancer, and breast tissue. To simplify the problem, real objects are replaced with the phantom. The phantom should have electrical and acoustic physics characteristics that are not much different from real objects. The material required as phantoms is gelatin, agar, graphite, glycerol, and distilled water.

The materials are made for the breast phantom which has electrical and acoustical properties appropriate with the data. The experiment set up in Figure 2(a) is a TAM device to obtain electrical data and Figure $2(b)$ is the principle of the TAM device. 


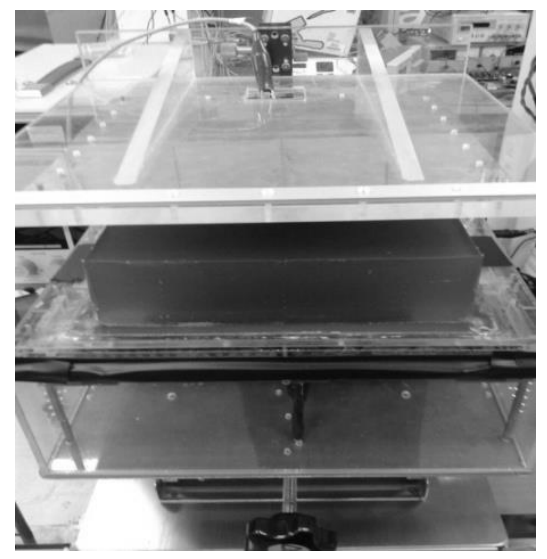

(a)

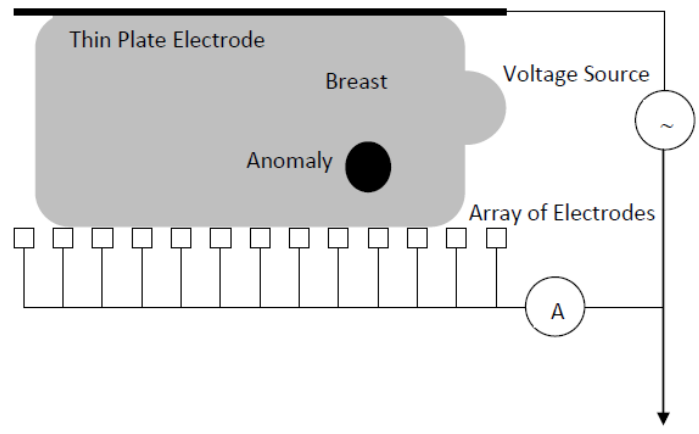

(b)

Figure 2 Experiment set up (a) the TAM system (b) the principle of TAM

Figure $3(a)$ is an ultrasound reflection device and Figure $3(b)$ is a schematic of reflection ultrasound to obtain the acoustic data.

The analysis is done by calculating the relative error of transversal $(x, y)$ and the depth (z) position. Relative error on transversal or depth position can be expressed as,

$$
\operatorname{error}(\%)=\frac{\xi_{i}-\xi_{0}}{l_{i}} \times 100 \%
$$

Where $\xi_{i}$ is anomaly position, $\xi_{0}$ is reference position, $l_{i}$ is a half of length $i$-axis and $i$ is $x, y, z$ axis. While the ratio analysis is conducted by comparing the calculation ratio towards the measurement ratio.

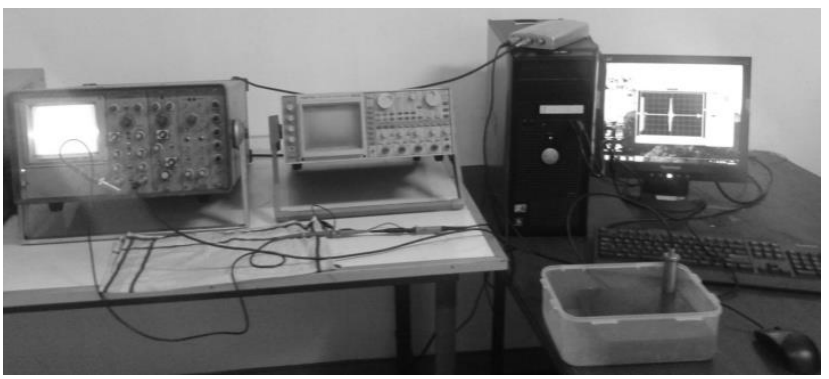

(a)

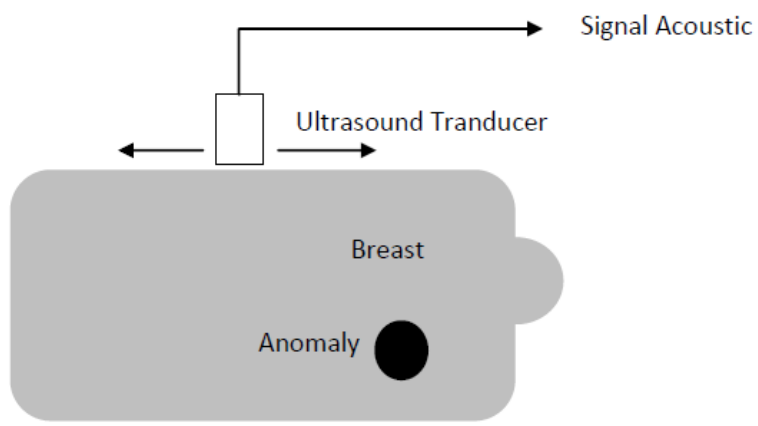

(b)

Figure 3 Experiment set up (a) acoustic reflection data of Ultrasound system (b) principle of ultrasound reflection

\subsection{RESULTS AND DISCUSSION}

The study uses the normal breast and the cancer phantom as an experiment object. Normal breast phantom is made from the composition of distilled water (1260 ml), agar (63.085 g), gelatin (191.621 g), and glycerol $(540 \mathrm{ml})$. Meanwhile, cancer phantom is made from the composition of distilled water $(88 \mathrm{ml})$, agar (3.281 g), gelatin (12.125 g), glycerol $(37.5 \mathrm{ml})$, sodium chloride $(0.500 \mathrm{~g})$ and carbon graphite $(6.125$ g). Sodium chloride and carbon graphite are added into the cancer phantom to produce the difference electric conductivity and acoustic impedance between normal breast and breast cancer.

The phantom was made by mixing all the ingredients and then heating it inside the microwave until it boils. Next, it is chilled in the mold, to configure normal and breast cancer phantom as shown in Figure 4.

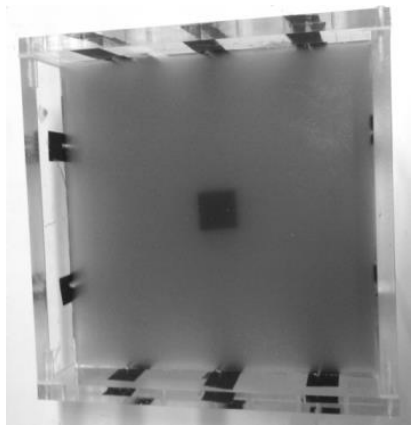

(a)

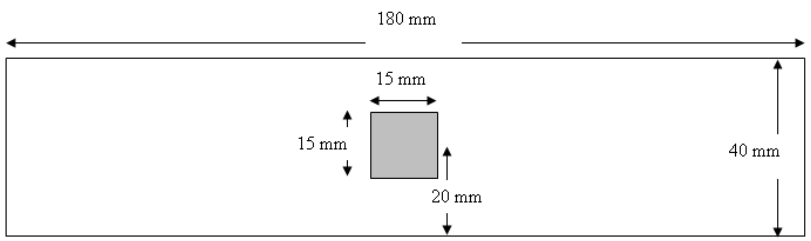

(b)

Figure 4 Normal breast and cancer phantom (a) phantom (b) configuration of phantom 
Figure 5 shows the electrical properties of the normal and breast cancer phantom which are tested using impedance/gain-phase analyzer at a frequency from $100 \mathrm{~Hz}$ to $1 \mathrm{MHz}$.

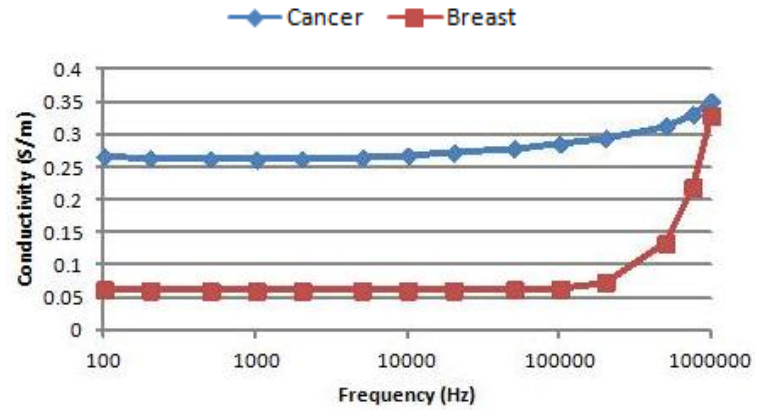

(a)

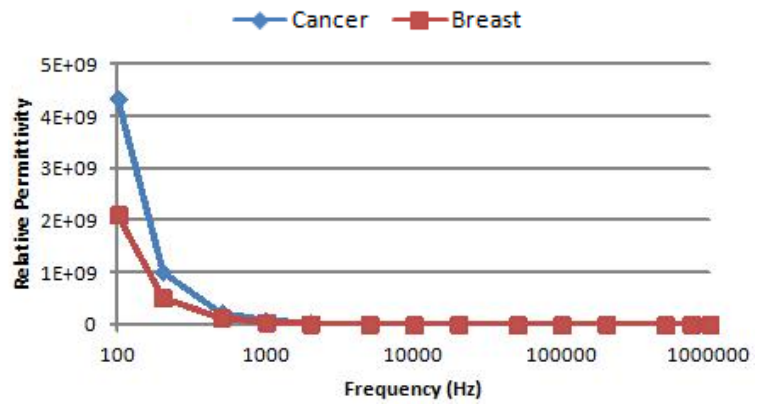

(b)

Figure 5 Electrical properties of normal and cancer breast phantom (a) The real data (conductivity) (b) imaginary data (relative permittivity)

The breast phantom is placed between the two electrodes of TAM devices, as showed in Figure 2(a). The process of data collection is conducted to obtain real and imaginary electric current data. The TAM devices have 3600 electrodes and it is operated in the frequency of $500 \mathrm{~Hz}, 1 \mathrm{kHz}, 5 \mathrm{kHz}, 10 \mathrm{kHz}, 50 \mathrm{kHz}$, and $100 \mathrm{kHz}$. The data are illustrated in Figures 6 and 7 .

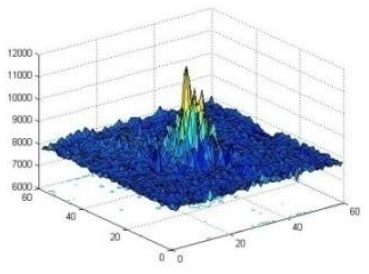

(a)

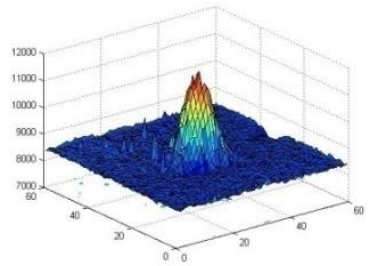

(c)

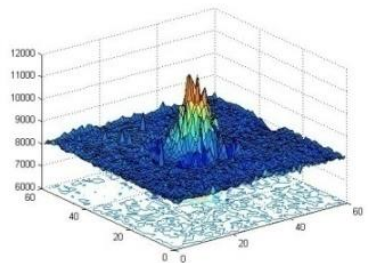

(b)

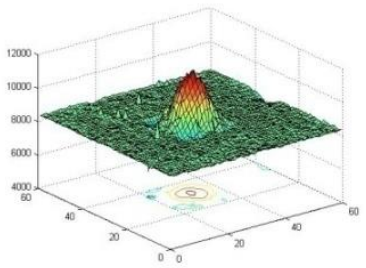

(d)

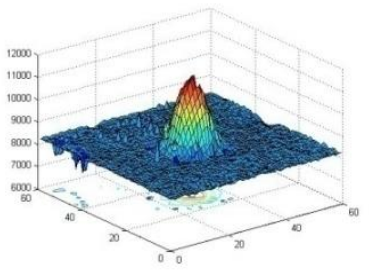

(e)

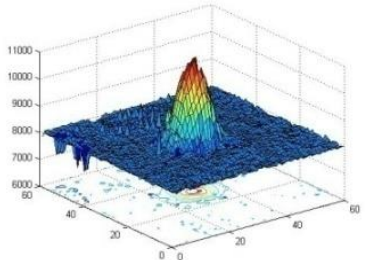

(f)
Figure 6 Real data in z-axis and transversal position in $x$-y axis in frequency of (a) $0.5 \mathrm{kHz}$,(b) $1 \mathrm{kHz}$, (c) $5 \mathrm{kHz}$, (d) $10 \mathrm{kHz}$, (e) $50 \mathrm{kHz}$, and (f) $100 \mathrm{kHz}$

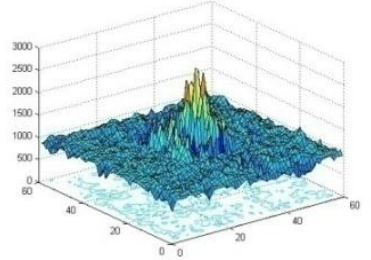

(a)

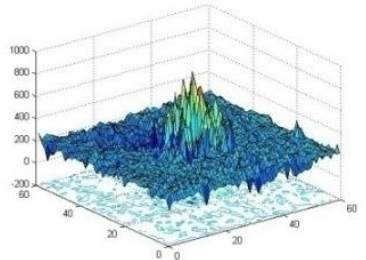

(c)

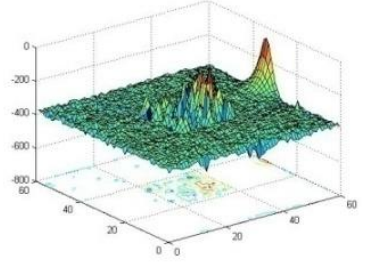

(e)

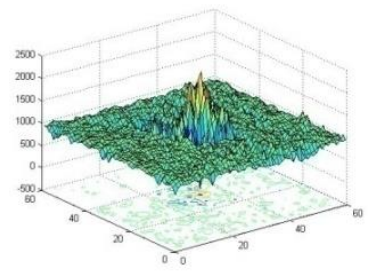

(b)

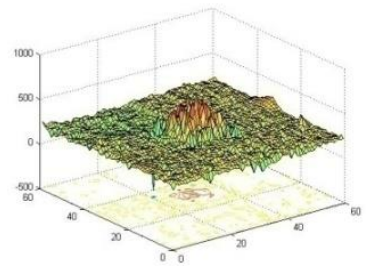

(d)

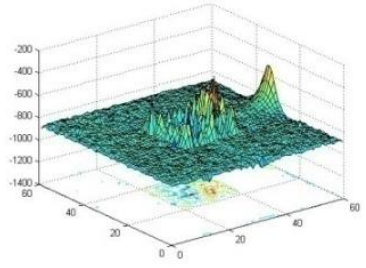

(f)
Figure $\mathbf{7}$ Imaginary data in z-axis and transversal position in $x-y$ axis in frequency of (a) $0.5 \mathrm{kHz}$, (b) $1 \mathrm{kHz}$, (c) $5 \mathrm{kHz}$, (d) 10 $\mathrm{kHz}$, (e) $50 \mathrm{kHz}$, and (f) $100 \mathrm{kHz}$

The data in Figures 6 and 7 were analyzed by using Equation (1), (2), and (3), in order to obtain transversal position and depth of the anomaly. The results are tabulated in Table 1.

Table 1 shows that analysis of the transversal position from the TAM can provide accurate results by an average error of $2.82 \%$ for real data and $2.32 \%$ for imaginary data, on the other hand, the depth position gives less accurate results by an average error $46 \%$ for real data and $28.3 \%$ for imaginary data. The accurate information of depth position is necessary to analyze volume or the ratio between anomaly conductivity and the reference conductivity from the Equation (3).

The experiment of ultrasound reflection is conducted by placing a transducer over the breast phantom and time of flight (TOF) is measured. The 
TOF is a time echo signal from the transducer into the object and backward the transducer. The TOF data are obtained by shifting the transducer as far as 5 $\mathrm{mm}$. Because phantom has a size of $18 \mathrm{~cm} \times 18 \mathrm{~cm}$, then there are $36 \times 36$ data. The set-up experiment of an ultrasonic reflection is displayed in Figure 3. If there is a difference in acoustic impedance, the transducers will acquire the signal reflection on the boundary.

A number of $36 \times 36$ TOF data was obtained to be converted into a signal envelope. The envelope signals are then arranged in three-dimensional space. The three-dimensional reconstruction image can be displayed as a two-dimensional slice in the $\mathrm{XZ}$ and yz axis as showed in Figure 8.

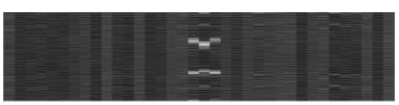

(a)

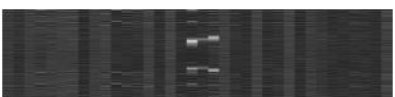

(b)

Figure 8 Reconstruction image of ultrasound reflection data (a) $x$-z slice (b) y-z slice

Analysis of transversal position, depth position, and volume anomalies in Figure 8 is conducted by measuring the ratio between the image of the surface boundary of anomalies and phantom anomaly size. The information on the transversal position, depth position, and volume anomalies can be obtained from Figure 8. The transversal position $x$ and $y$ are at the center of the ordinate. The depth of anomaly is $18 \mathrm{~mm}$ from the surface with a $10 \%$ error. The anomaly volume is $(15 \times 15 \times 14) \mathrm{mm} 3$ with a $0.03 \%$ error. The acoustic reflection system can generate position information better than the trans-admittance system.

Data on electric properties from TAM and acoustic properties from the ultrasound system can be combined to obtain an accurate transversal position, depth position, volume anomalies, and ratio anomaly as background by utilizing the depth data and volume anomalies from the ultrasound reflection, they are reported in Table 2. It appears that ratio accuracy depends on the frequencies used.

Basically, the TAMUR dual-modality system is a combination of an ultrasound reflection system that has the ability to obtain the depth and anomaly volume and electrical properties from the TAM system to obtain the information of ratio anomaly conductivity and reference. The analysis combined electrical parameters from the TAM and acoustic parameters from the ultrasound reflection system will obtain the transversal position, the depth position, volume, and the ratio of anomalies to reference accurately. In summary, the comparison among the three systems, namely the TAM, ultrasound reflection (UR), and TAMUR is displayed in Table 3.
Table 1 Analysis of experiment data using reference frequency $\omega_{0}=500 \mathrm{~Hz}$

\begin{tabular}{|c|c|c|c|c|c|c|c|c|c|}
\hline \multicolumn{4}{|c|}{ Phantom } & \multicolumn{6}{|c|}{ Real data } \\
\hline & & & & \multicolumn{4}{|c|}{ Transversal } & \multicolumn{2}{|c|}{ depth } \\
\hline $\begin{array}{l}\text { Freq. } \\
(\mathrm{kHz})\end{array}$ & $X$ & $\mathrm{Y}$ & Z & $\begin{array}{c}\mathrm{X} \\
\mathrm{mm}\end{array}$ & $\begin{array}{c}\text { Error } \\
(\%)\end{array}$ & $\begin{array}{c}\mathrm{Y} \\
\mathrm{mm}\end{array}$ & $\begin{array}{c}\text { Error } \\
(\%)\end{array}$ & $\begin{array}{c}\mathrm{Z} \\
\mathrm{Mm} \\
\end{array}$ & $\begin{array}{c}\text { Error } \\
(\%)\end{array}$ \\
\hline 1 & 0 & 0 & 20 & 1.32 & 1.47 & 3.20 & 3.56 & 11.5 & 42.5 \\
\hline 5 & 0 & 0 & 20 & 1.32 & 1.47 & 1.93 & 2.14 & 11.8 & 41 \\
\hline 10 & 0 & 0 & 20 & 1.32 & 1.47 & 10.01 & 11.12 & 8.2 & 59 \\
\hline 50 & 0 & 0 & 20 & 1.32 & 1.47 & 1.89 & 2.10 & 10.5 & 47.5 \\
\hline 100 & 0 & 0 & 20 & 1.32 & 1.47 & 1.75 & 1.94 & 12.0 & 40 \\
\hline \multicolumn{4}{|c|}{ Average } & & 1.47 & & 4.17 & & 46 \\
\hline \multirow{2}{*}{\multicolumn{4}{|c|}{ Phantom }} & \multicolumn{6}{|c|}{ Imaginary data } \\
\hline & & & & \multicolumn{4}{|c|}{ Transversal } & \multicolumn{2}{|c|}{ depth } \\
\hline $\begin{array}{l}\text { Freq. } \\
(\mathrm{kHz})\end{array}$ & $X$ & $Y$ & Z & $\begin{array}{c}\mathrm{X} \\
\mathrm{mm}\end{array}$ & $\begin{array}{c}\text { Error } \\
(\%)\end{array}$ & $\begin{array}{c}\mathrm{Y} \\
\mathrm{mm}\end{array}$ & $\begin{array}{c}\text { Error } \\
(\%)\end{array}$ & $\begin{array}{c}\mathrm{Z} \\
\mathrm{Mm}\end{array}$ & $\begin{array}{c}\text { Error } \\
(\%)\end{array}$ \\
\hline 1 & 0 & 0 & 20 & 0.09 & 0.10 & 4.07 & 4.52 & 14.7 & 26.5 \\
\hline 5 & 0 & 0 & 20 & 1.14 & 1.27 & 3.06 & 3.4 & 15.7 & 21.5 \\
\hline 10 & 0 & 0 & 20 & 1.15 & 1.28 & 3.07 & 3.41 & 15.7 & 21.5 \\
\hline 50 & 0 & 0 & 20 & 1.09 & 1.21 & 3.04 & 3.38 & 12.2 & 39 \\
\hline 100 & 0 & 0 & 20 & 1.06 & 1.18 & 3.03 & 3.37 & 13.4 & 33 \\
\hline \multicolumn{4}{|c|}{ Average } & & 1.01 & & 3.62 & & 28.3 \\
\hline
\end{tabular}

Table 2 Analysis of conductivity ratio of breast and cancer phantom by using reference frequency of $500 \mathrm{~Hz}$

\begin{tabular}{llllll}
\hline $\begin{array}{l}\text { Frequen } \\
\text { cy (kHz) }\end{array}$ & $\begin{array}{l}\text { Cancer } \\
\text { phantom } \\
\text { conduc } \\
\text { Tivity }\end{array}$ & $\begin{array}{l}\text { Breast } \\
\text { phantom } \\
\text { conduc } \\
\text { tivity }\end{array}$ & $\begin{array}{l}\text { Ratio } \\
\text { from } \\
\text { measur } \\
\text { ements }\end{array}$ & $\begin{array}{l}\text { Ratio } \\
\text { from } \\
\text { predi } \\
\text { ction }\end{array}$ & $\begin{array}{l}\text { Error } \\
\text { (\%) }\end{array}$ \\
\hline 0.5 & 0.262 & 0.062 & 4.260 & & \\
1 & 0.262 & 0.061 & 4.267 & 4.489 & 5.20 \\
5 & 0.265 & 0.061 & 4.334 & 3.689 & 14.88 \\
10 & 0.268 & 0.061 & 4.382 & 5.257 & 19.97 \\
50 & 0.279 & 0.062 & 4.498 & 3.448 & 23.34 \\
100 & 0.286 & 0.064 & 4.433 & 6.730 & 51.82 \\
\hline
\end{tabular}

Table 3 Comparison among TAM, UR and TAMUR

\begin{tabular}{|c|c|c|c|c|}
\hline & $\begin{array}{c}(x, y) \\
\text { position }\end{array}$ & $\begin{array}{c}\text { (z) } \\
\text { position }\end{array}$ & Volume & $\tau_{\text {anomaly }} / \tau_{\text {reference }}$ \\
\hline \multirow[t]{2}{*}{ TAM } & accurate & low & Prediction & Prediction \\
\hline & & accurate & & \\
\hline UR & accurate & Accurate & Accurate & --- \\
\hline TAMUR & accurate & Accurate & Accurate & Accurate \\
\hline
\end{tabular}

This study still uses a simple phantom with a single anomaly, according to the models in Equation (1), (2), and (3). In further research, it is recommended to use phantom with more than one anomaly and or with different electrical conductivity according to real conditions. Therefore it is also necessary to modify the Equations (1), (2), and (3) to accommodate the real case.

\subsection{CONCLUSION}

The TAM device is not able to inform the volume of an anomaly, but can provide the information about the transversal position and depth of the anomaly by an average error of $2.57 \%$ and $37.15 \%$ respectively. The ultrasound reflection device can inform the 
depth of ultrasonic reflection and anomaly volume by an error of $10 \%$ and $0.03 \%$ respectively. The TAM device is only able to predict the anomaly volume from the prediction of conductivity ratio. However, the combination of depth and anomaly volume from ultrasonic reflection data on the TAM device can provide the right information for the ratio of conductivity anomalies and reference. The dualmodality TAMUR is expected to be applied to analyze multi anomalies that correspond to a real case. High contrast data from trans-admittance and high accuracy in determining the transversal position can be used as a guiding presence and location of anomalies in the transversal position. The transversal position information is then used as the prior information on the ultrasonic reflection system to obtain position information of the depth and multivolume anomalies.

\section{Acknowledgement}

This study was supported by The Ministry of Research, Technology, and Higher Education of the Republic of Indonesia (711/UN3.14/LT/2019) and the Institute of Technology Bandung. We would like to thank the IIRC laboratory of Kyung Hee University has supported the TAM device.

\section{References}

[1] Ain, K., Kurniadi, D., Soeprijanto, Santoso, O. 2017. Dual Modality Electrical Impedance and Ultrasound Reflection Tomography to Improve Image Quality. Journal of Electrical Bioimpedance. 3: 3-10.

[2] Arad, M., Adunsky, A. 2010. Diagnosis of Elderly Pneumonia Patients Using a Parametric Electrical Impedance Tomography System-A Preliminary Study. Int. J. Medical Engineering and Informatic. 2(4): 355-363.

[3] Bera, T. K., and Nagaraju, J. 2014. Studying the Resistivity Imaging of Practical Phantoms with Common Ground Current Injection Technique in Electrical Impedance Tomography. Int. J. Communication Networks and Distributed System. 12(1): 47-68.

[4] Bijwaard, H., Brenner, A., Dekkers, F., Dillen T. V., Land C. E, Boice J. D. 2010. Breast Cancer Risk from Different Mammography Screening Practices. Radiat Res. 174: 367-376.

[5] Breast Cancer Facts \& Figures. 2015-2016. The American Cancer Society, Atlanta. (https://www.cancer.org/research/cancer-factsstatistics/breast-cancer-facts-figures.html).

[6] Cherepenin, V. A., Karpov, A. Y., Korjenevsky, A. V., Kornienko, V. N., Kultiasov, Y. S., Ochapkin, M. B., Trochanova, O. V., and Meister, J. D. 2002. ThreeDimensional EIT Imaging of Breast Tissues: System Design and Clinical Testing. IEEE Transactions on Medical Imaging. 21 (6): 662-667.

[7] Holder, D. S. 2005. Electrical Impedance Tomography, Methods History and Application. Institute of Physics Publishing, Bristol and Philadelpia.

[8] Hope, T. A. and lles, S. E. 2004. Technology Review: The Use of Electrical Impedance Scanning in the Detection of Breast Cancer. Breast Cancer Res. 6: 69-74.
[9] Hu, G., and He, B. 2011. Magneto-acoustic Imaging of Electrical Conductivity of Biological Tissues at a Spatial Resolution Better than $2 \mathrm{~mm}$. PLOS ONE. 6(8).

[10] Jemal, A., Bray, F., Center, M. M., Ferlay, J., Ward, E., and Forman, D. 2011. Global Cancer Statistics. CA Cancer Journal CLIN. 61 (2): 69-90. DOI: 10.3322/caac.20107.

[11] Jossinet, J. 1998. The Impedivity of Freshly Excised Human Breast Tissue. Physiol. Meas. 19: 61-75.

[12] Kao. T. J, Saulnier, G. J., Xia, H., Tamma, C., Newell, J C. and Isaacson, D. 2007. A Compensated Radiolucent Electrode Array for Combined EIT and Mammography. Physiological Measurement. 28(7): S291-S299.

[13] Kerner, T. E., Paulsen, K. D., Hartov, A., Soho, S. K., and Poplack, S. P. 2002. Electrical Impedance Spectroscopy of the Breast: Clinical Imaging Results in 26 Subjects. IEEE Transactions on Medical Imaging. 21 (6): 638-645.

[14] Keshtkar, A., Mesbahi, A., and Mehnati, P. 2008. The Effect of Bladder Volume Changes on the Measured Electrical Impedance of the Urothelium. Int. J. Biomedical Engineering and Technology. 1 (3): 297-292.

[15] Lee, C. H., D. Dershaw, D., Kopans, D., Evans, P. Monsees, B., Monticciolo, D., Brenner, R. J., Bassett, L., Berg, W., Feig, S., Hendrick, E., Mendelson, E., D'Orsi, C., Sickles, E., and Burhenne, L. W. 2010. Breast Cancer Screening with Imaging: Recommendations from the Society of Breast Imaging and the ACR on the Use of Mammography, Breast MRI, Breast Ultrasound, and Other Technologies for the Detection of Clinically Occult Breast Cancer. Journal American College of Radiology. 7(1): 18-27. DOI: 10.1016 / j.jacr.2009.09.022.

[16] Lee, J. H., Kim, S. H., Kim, S., Seo, J. K., Zribi, H., Woo, E. J. 2007. New Anomaly Detection Algorithm Using Multi Frequency Trans-admittance Maps. $13^{\text {th }}$ International Conference on Electrical Bio-impedance and the $8^{\text {th }}$ Conference on Electrical Impedance Tomography, IFMBE Proceedings. 17: 392-395.

[17] Oh, T. I., Lee, J., Seo, J. K., Kim, S. W., and Woo, E. J. 2007. Feasibility of Breast Cancer Lesion Detection Using a Multi-frequency Trans-admittance Scanner (TAS) with 10 $\mathrm{Hz}$ to $500 \mathrm{kHz}$ Bandwidth. Physiol. Meas. 28: S71-S84, 7184. Doi:10.1088/0967-3334/28/7/S06.

[18] Omoleke, S. A. and Lawal, I. 2016. Cancer Care in Developing Countries: Does Early Detection Truly Save Lives. Journal of Women's Health Care. 5(2). DOI:10.4172/2167-0420.1000305.

[19] Prasad, S. N.,Houserkova D, Campbell J. 2008. Breast Imaging using 3D Electrical Impedence Tomography. Biomed Pap Med Fac Univ Palacky Olomouc Czech Repub. 15(1): 151-154.

[20] Sardanelli, F., Giuseppetti, G. M., Panizza, P., Bazzocchi, M., Fausto, A., Simonetti, G., Lattanzio, V., Maschio, A. D. 2004. Sensitivity of MRI Versus Mammography for Detectingfoci of Multifocal, Multicentric Breast Cancer in Fatty and Dense Breasts Using the Whole-breast Pathologic Examination as a Gold Standard. American Journal of Roentgenology. 183(4): 1149-1157.

[21] Saslow, D., Boetes, C., Burke, W., Harms, S., Leach, M. O. Lehman, C. D., Morris, E., Pisano, E., Schnall, M., Sener, S. Smith, R. A., Warner, E., Yaffe, M., Andrews, K. S., Russell, C. A. 2007. American Cancer Society Guidelines for Breast Screening With MRI as an Adjunct to Mammography. CA: A Cancer Journal for Clinicians. 57(2): 75-89. DOI: 10.3322/canjclin.57.2.75.

[22] Seo, J. K., Kwon, O., Ammari, H., and Woo, E. J. 2004. A Mathematical Model for Breast Cancer Lesion Estimation: Electrical Impedance Technique Using TS2000 Commercial System. IEEE Transactions on Biomedical Engineering. 51 (11): 1898-1906.

[23] Shao, W. and Adams, R. S. 2012. Multi-polarized Microwave Power Imaging Algorithm for Early Breast Cancer Detection. Progress in Electromagnetic Research. 23: 93-107. 
[24] Surowiec, A. J., Stuchly, S. S., Barr, J. R., and Swarup, A. 1998. Dielectric Properties of Breast Carcinoma and the Surrounding Tissues. IEEE Transactions on Biomedical Engineering. 35(4): 257-263.

[25] Zhang, T., Lee, E., and Seo, J. K. 2014. Anomaly Depth Detection in Trans-admittance Mammography: A Formula Independent of Anomaly Size or Admittivity Contrast. Inverse Problems. 8: 1-22. DOI:10.1088/0266$5611 / 30 / 4 / 045003$.
[26] Zhao, M., Wi, H., Oh, T. I., Woo, E. J. 2013. Evaluation of Anomaly Detection Algorithm Using Trans-Admittance Mammography with $60 \times 60$ Electrode Array. Engineering in Medicine and Biology Society (EMBS). 35th Annual International Conference of the IEEE EMBS. 6433-6436.

[27] Zou, Y. and Guo, Z. 2003. A Review of Electrical Impedance Technique for Breast Cancer Detection. Medical Engineering and Physics. 25: 79-90. 